real risk of sensitisation of patients receiving dialysis to human leucocyte antigens, which may make matching for a transplant difficult or impossible. A successfully transplanted kidney produces erythropoietin such that the anaemia of chronic renal failure is corrected by three to four months after transplantation. Unfortunately, the number of patients waiting for a graft kidney is increasing year by year. Perhaps two fifths of all dialysis patients are too old or too infirm to hazard the risk of transplant surgery and immunosuppression.

An obvious way forward when the renal budget is too small is to ask the patient's general practitioner to prescribe the hormone. This arrangement exists for growth hormone. The Secretary of State for Health has specifically directed that growth hormone, which costs $£ 5000-£ 10000$ a year (supplier's estimate) should be prescribed by family doctors. Many general practitioners are prescribing erythropoietin, but not all are happy to do so.

Some think that it is improper to prescribe drugs for patients whose treatments are not directly under their clinical control, ${ }^{6}$ and they cite the Department of Health's backing for this position. It has issued reminders to practitioners that prescribers should be in clinical control of all patients for whom they prescribe. Presumably this is yet another attempt to restrict funding without consideration for patients' welfare and contradicts previous statements from the Department of Health that all who require a drug will receive it.

The way around this difficulty? Reluctant general practitioners should be asked to take full responsibility for their patients' welfare and renal physicians should provide just advice when the patient is not in hospital. The time and effort that this would take for a few hundred patients would be well worth while. Erythropoietin so improves the quality of life in selected patients that to withhold it, in 1991, in the United Kingdom is unacceptable.

\section{ROGER GABRIEL}

Renal Physician,

St Mary's Hospital,

London W2 1NY

1 Challah S, Wing AJ, Bauer R, Morris RW, Schroeder SA. Negative selection of patients for dialysis and transplantation. $B M \mathcal{F} 1984 ; 288: 1119-22$.

Berlyne GM. Over 50 and uraemic = death. The failure of the British National Health Service to provide adequate dialysis facilities. Nephron 1982;31:189-90.

3 Taylor J, Henderson IS, Mactier RA. Erythropoietin withdrawal. BM7 1991;302:272-3.

4 Schaefer RM, Hörl WH, Massry SG. Treatment of renal anemia with recombinant human erythropoietin. Am F Nephrol 1989;9:353-62.

5 Gabriel R. Wanted: funds for a treatment that really works. $B M \mathcal{1}$ 1989;299:64.

6 Bogle I. Passing on problems to the general practitioners. Independent on Sunday $1990 \mathrm{Dec}$ 2:17(col 6).

\title{
Prospective or retrospective: What's in a name?
}

\section{The shorthand classification of a study may create confusion}

The recent adoption of the more informative structured abstract by several medical journals has rehashed an old debate on the use of the words "prospective" and "retrospective" in clinical and epidemiological research. ${ }^{1}$ The structured abstract requires a description of the study design. Editors like it to be crisp and clear and, above all, short. Hence the words prospective and retrospective have started a second life- and seeded new confusion.

Epidemiology knows of two schools of thought regarding the use of these words. One school, originally centred on epidemiologists at Johns Hopkins, calls any follow up study prospective even if it is clearly a historical cohort, ${ }^{23}$ maintaining that any follow up moves forward in time. They therefore use the word retrospective for what the other school calls "case-control." Their reasoning is that in the casecontrol study the investigator in effect looks back from present disease to past exposure. The other school, originally centred on Harvard, ${ }^{+}$knows of two types of follow up studies - the prospective and the retrospective-both distinct from case-control research. According to the second tradition, the strictest definition of a prospective study might run thus: a follow up study in which a disease outcome is related to baseline characteristics that were originally collected with this particular follow up in mind. The investigators collected the baseline information according to a protocol that included the follow up and then aged together with their subjects. In contrast, in a retrospective follow up study the investigator has a bright idea, searches some conveniently available dataoriginally collected for other purposes - and adds a follow up about his or her favourite disease up to the present. The second school maintains that it sticks to the common use of the prefixes "retro" and "pro," as indicators of the time course of a study from the point of view of the investigator. ${ }^{4}$

In the past feelings ran high, and present positions remain entrenched. The Dictionary of Epidemiology still calls "cohort," "follow up," and "prospective" synonyms, irrespective of whether the data are past or present, ${ }^{5}$ while clinical epidemiologists and theoreticians detail all the distinctions. ${ }^{67}$ Smart researchers have, of course, learnt that the chances of funding and publication are improved by calling a study prospective. The qualifier retrospective has been defamed too often in the past, accused of all the potential biases of case-control research. ${ }^{8}$

In the $B M Y$ 's recent clinical and epidemiological papers adorned with the new type of abstract the word prospective abounds. A closer look at the details of the methods in these papers, however, soon shows that the use of the word wildly transgresses the boundaries of the venerable epidemiological conflict of terminologies. Several case series are called prospective, apparently because the patients were entered consecutively, even when there is no inkling of any prespecified research plan: data were retrieved from more or less consecutive old records because of a new interest. Oddly enough, plain case-control comparisons within such patient series also happen to be labelled prospective, presumably because the patients accrued over a specified period. Almost all follow up studies, whether of past or present cohorts, wave prospective flags. Some are prospective according to the strictest definition. In others researchers who retrieved an old population survey, a previous case series, or a forgotten clinical trial and who added a further follow up for a purpose unrelated to the original venture proceed to call the amalgam prospective. Furthermore, when data from a follow up study of whatever sort are reanalysed for a new purpose the new publication almost invariably retains the label prospective; the proper name should, of course, be "secondary analysis." Finally, a common superfluous use of the word is in the expression "prospective randomised controlled trial." As people cannot be randomised in the past a randomised controlled trial cannot be anything but prospective. Given the confusionwhich is not limited to this journal - the words prospective and retrospective have lost all meaning. From spotting them 
in the abstract the reader gains no insight into the type of research that was performed.

About the only people who defiantly call their own studies retrospective seem to be those engaged in medical audit research. They know that audit can be done only after the facts. Yet, in reality almost all clinical follow up studies are retrospective - pace Hopkins - and rightly so: doctors want to study the disease outcome in their former patients as a guidance for the future. New ideas to delineate new syndromes or to extract new learning from old material abound in clinical medicine. Most occupational health studies, investigating the long term health effects of occupational exposures, are of the retrospective follow up type. Late follow ups of old clinical trials in oncology to detect beneficial or adverse effects with long latency are another good example.

The creative and opportunistic exploitation of old data should command the admiration of anyone who has a feel for aesthetics and efficiency in research. ${ }^{9}$ A real prospective follow up - that is, starting afresh with a new collection of baseline data - is necessary only when the research clearly gains by the more specific, albeit tedious, collection of novel data and by the laborious tracing of individuals when follow up events slowly accrue over time. ${ }^{7}$ Otherwise, the elegant and leisurely use of existing data, permitting very long term follow up of large numbers at minimum cost, is preferable. Even more efficient is the secondary analysis of clinical and epidemiological data, which is an exercise of great value given that the original investment in data collection has often been huge and cannot be replicated easily. At the same time the potential weaknesses need acknowledging: the investigators were not masters of the original data collection, and retrospective and secondary analyses are more prone to the hazards of data dredging. In this regard the consumers of research, the readers of journals, have the right to expect meaningful information from the more informative abstract. The most precise solution might be to abandon the use of the words prospective and retrospective altogether in favour of short descriptions of what actually happened.

JAN P VANDENBROUCKE

Professor of Clinical Epidemiology,

Leiden University Hospital, Bldg 1-C0-P,

P O Box 9600 ,

2300 RC Leiden,

The Netherlands

1 Haynes RB, Mulrow CD, Huth EJ, Altman DG, Gardner MJ. More informative abstracts revisited. Ann Intern Med 1990;113:69-76.

2 Sartwel PE. Trends in epidemiology. In: Stewart GT, ed. Trends in epidemiology. Springfield, Illinois: Thomas, 1972:17-8.

3 Lilienfeld AM. Foundations of epidemiology. New York: Oxford University Press, 1976:164-214 4 MacMahon B, Pugh TF. Epidemiology, principles and methods. Boston: Little, Brown, 1970:43-4. 5 Last JM, ed. A dictionary of epidemiology. 2nd ed. New York: Oxford University Press, 1988:26. 6 Feinstein AR. Clinical epidemiology: the architecture of clinical research. Philadelphia: Saunders, 198 Miettinen OS. Theoretical epidemiology: principles of occurrence research in medicine. New York: Wiley, 1985

8 Anonymous. Should we case-control? [Editorial] Lancet 1990;335:1127-8.

9 Fraser DW. Epidemiology as a liberal art. N Engl f Med 1987;316:309-14.

\title{
Revisiting the internal market
}

\author{
And finding it's all gone slow
}

Alain Enthoven, father of the internal market, was in England last week to assess progress in implementing the NHS reforms. His plan to introduce competition among hospitals to stimulate efficiency, published in $1985,{ }^{1}$ had an appreciable influence on the ministerial review of the NHS. Although Enthoven described his ideas as involving "a kind of market socialism," they had a strong appeal to a Conservative government that rejected more radical options for change.

As Enthoven visited hospitals and talked to doctors and managers what will he have found? To outward appearances the reforms are very much on course. The proposals set out in the white paper Working for Patients almost exactly two years ago have been enshrined in the NHS and Community Care Act, and the internal market is scheduled to begin on 1 April.

Beneath the surface, however, it is clear that the emphasis has changed considerably for those charged with steering implementation through. Several developments in recent months suggest that ministers are running scared of competition and are intent on controlling the market tightly from the centre. This represents less of a $U$ turn than an unwillingness to let the reforms function as originally intended - at least for the time being.

The first indication of the change of approach came last March when senior officials announced that little would alter in where services are provided in the first instance. This was variously characterised as "steady state," "no surprises," and "smooth takeoff." But the message was clear - the government did not expect to see much competition among hospitals until the new arrangements for contracting for services had bedded in.

This message was reinforced in July when health authorities were asked to undertake a stocktaking exercise of their plans for contracting. The exercise entailed health authorities providing information to the Department of Health on their plans for buying and selling services. As part of this process health authorities were advised to concentrate on block contracts to begin with rather than cost and volume and cost per case contracts, which were perceived to involve greater risks and uncertainties.

In submitting their reports authorities were asked to identify large variations in how services were provided. They were also requested to confirm that these variations had been planned for and were manageable. In addition, the Department of Health asked for information on how authorities planned to "manage the risk" of hospitals that depend heavily on income from patients who are referred outside of contracts.

The nervousness of those at the centre was further exemplified by an internal Department of Health memorandum on the effects of the reforms in London that was leaked to the Labour party. The memorandum identified a strong possibility that health authorities outside London might decide to treat patients locally instead of referring them to London's teaching hospitals. The reasons for this included lower costs in the shire counties and the existence of spare capacity.

The memorandum went on to record that general practitioners holding budgets for the first time might change their referral patterns in the same way. The effect would be to destabilise hospital provision in London, leading to piecemeal closures and cutbacks. Although the memorandum acknowledged that a reduction in hospital provision in London was probably desirable, it drew the attention of ministers to the danger of this occurring in an unplanned way.

The London memorandum was closely linked to the 